\title{
The aromatase expression in myomas and myometriums of women in reproduction and perimenopausal age
}

\author{
Paweł Madej1, Andrzej Plewka ${ }^{2}$, Danuta Plewka ${ }^{3}$, Piotr Paleń ${ }^{4}$, Grażyna Nowaczyk ${ }^{3}$, \\ Edyta Bogunia² ${ }^{2}$ Jacek Marczyński², Józef Waloszek²
}

\author{
${ }^{1}$ Chair and Departament of Gynaecological Endocrinology, Medical University of Silesia, \\ 40-752 Katowice, Poland \\ 2Department of Proteomics, Medical University of Silesia, Sosnowiec, Poland \\ ${ }^{3}$ Department of Histology, Medical University of Silesia, Katowice, Poland \\ ${ }^{4}$ Department of Histopathology, Medical University of Silesia, Katowice, Poland
}

\begin{abstract}
Uterine myomas represent one of the most common female pathologies. Uterine smooth muscle myomas or fibromas are benign tumours which respond to hormones and their etiology induces wide interest. The myomas were found to contain aromatase and, in addition, cells of the myomas were found to synthesize estrogen. This study was conducted on patients with the myomas, in either generative age or in the perimenopausal period. Expression of aromatase was detected in patients of various age, with large or small uterine myomas, using an immunohistochemical technique. In addition expression of the enzyme was examined at the periphery of every myoma.
\end{abstract}

Key words: aromatase, leiomyomas, small and large leiomyoma, women

\section{Introduction}

Despite the high frequency in which smooth muscle myomas develop, the knowledge on their development and growth remains incomplete. On the basis of multiple studies, including cytogenetic ones, every smooth muscle myoma is thought to represent a product of clonal expansion of a single myocyte $[1,2]$. Similarly to the situation noted in other tumours, most probably genetically sensitive sites exist, the mutation of which leads to loss of control over smooth muscle proliferation and to a transformation of a smooth muscle cell to yield a common phenotype of a smooth muscle myoma cell.

The neoplastic transformation of smooth muscles to a smooth muscle myoma probably involves somatic mutations of genes important in proliferation and apoptosis of normal myometrium and in complex interactions between sex steroids and growth factors $[3,4]$. The observations have provided investigators with an insight into myoma pathophysiology and have

Correspondence: A. Plewka, Department of Proteomics,

Medical University of Silesia, ul. Ostrogórska 30,

41-200 Sosnowiec, Poland; tel.: (+4832) 3641430,

fax.: (+4832) 3641440, e-mail: aplewka@sum.edu.pl yielded the first key to recognise growth potential of the ovarian steroid-dependent tumours. Nevertheless, the role of steroids and of other growth factors in initiation and growth of the tumours still remains only partially recognised.

A marked number of experimental and clinical data indicate that estrogen stimulates growth of uterine smooth muscle myomas $[5,6]$. In the middle of 1970-ties, detection that smooth muscle myomas carry estrogen receptors additionally backed up the hypothesis that smooth muscle cell myomas at least partially are dependent on estrogen [7]. It was also noted that, as compared to normal myometrium, smooth muscle cell myomas contained increased levels of the receptors $[8,9]$.

In 1994, Bulun et al. [10] detected presence of aromatase in smooth muscle cell myomas. As compared to the surrounding myometrium, smooth muscle cell myomas contained eleveted levels of aromatase and were able to synthesize estrogen $[10,11]$ while tissue concentrations of estrogen were augmented in smooth muscle cell myomas as compared to the surrounding myometrium $[12,13]$. In addition, in vitro experiments proved that estrogen synthesized in smooth muscle cells in a culture was sufficient to support proliferation 
in an intracrine manner, since stimulation of aromatase activity increased cell proliferation while an aromatase inhibitor reduced the proliferation [11].

Studies on correlation between levels of aromatase mRNA disclosed a positive trend between the levels and progressing age of the patients. This would suggest that local expression of aromatase may be a significant variable which determines availability of estrogen for myoma tissues even if the levels of circulating estrogen are markedly lowered in peri- and postmenopausal women.

Determination of aromatase expression in the tumour cells and cells of other estrogen-dependent tumours is significant for disclosing pathogenesis of the tumours and for defining potential directions of their therapy. An increasing number of studies suggests that in women of post-menopausal age estrogens localised in tumour cells originate from in situ aromatization in the pathologically changed tissue and they act there as a mitogenic factor, promoting tumour growth independently of estrogen concentrations in the serum.

Clinical studies of the earlier operated women demonstrate frequent development of novel neoplastic foci in myometrium. This study aimed at an attempt to demonstrate possible presence of potentially neoplastic cells in the margins of healthy tissue, which was removed together with the primary tumour. Our earlier studies [14] indicate, that healthy myometrium taken $4 \mathrm{~cm}$ from myomas demonstrated active telomerase like tumor cells.

Thus the aim of our study is to detect telomerase expression in myoma cells and demonstrate its activity in healthy myometrium in relation to the distance from pathological lesion, assuming low activity of the enzyme in normal cells and markedly higher one in myoma cells.

\section{Materials and methods}

Human material. Recruitment of patients, clinical studies and hormonal tests will be conducted in the Chair and Department of Gynaecological Endocrinology, Medical University of Silesia in Katowice while enzymatic and protein studies will be executed in the Department of Proteomics.

The studies were conducted on 40 patients with myomas, at the reproductive age (below 45 th year of age, $\mathrm{FSH}<30 \mathrm{mIU} / \mathrm{ml}$; samples were taken in follicular phase of menstrual cycle) and 40 patients with myomas in the perimenopausal age (45-55 years of life, FSH $>30 \mathrm{mIU} / \mathrm{ml}$ ). Inclusion criteria will involve myomas detected by USG, qualification of the patient to hysterectomy, informed consent to the planned studies. The exclusion criteria will include: therapy with any drugs, including hormonal drugs in the minimum of 3 months before inclusion to the studies, neoplastic disease, endometrial hypertrophy, metabolic and systemic disturbances, nicotinism.

Myometrial samples, for use as health controls were taken from 10 young women $(<40$ years old) undergoing hysterectomies for ovary tumors and 10 older women ( $>52$ years old) undergoing hysterectomies for uterine prolapse.
The material for studies was sampled intraoperatively. Samples of myoma $1 \times 1 \mathrm{~cm}$ and samples of a similar size from healthy myometrium at the distance of at least $4 \mathrm{~cm}$ each were taken.

Before isolation of myometrium samples the patients were informed on the aim of the studies. The planned investigative procedures were approved by the Medical Bioethical Commission.

\section{Characteristics of studied groups.}

Group 1. Myometrium of menstruating women, in whom hysterectomy was performed for reasons other than uterine leiomyomas; the 10 patients represented the lesion-free control.

Group 2. Leiomyomas of $<3 \mathrm{~cm}$ in diameter, sampled from uteri of menstruating women ( $\mathrm{n}=20$ women).

Group 3. Myometrium of menstruating women, sampled at the distance of not less than $4 \mathrm{~cm}$ from margins of a small leiomyoma ( $\mathrm{n}=20$ women; autologous control).

Group 4. Leiomyomas of $>5 \mathrm{~cm}$ in diameter, sampled from uteri of menstruating women ( $n=20$ women).

Group 5. Myometrium of menstruating women, sampled at the distance of not less than $4 \mathrm{~cm}$ from margins of a large leiomyoma ( $\mathrm{n}=20$ women; autologous control).

Group 6. Myometrium of non-menstruating women, in whom hysterectomy was performed for reasons different than uterine leiomyomas ( $\mathrm{n}=10$ women; lesion-free control).

Group 7. Leiomyomas of $<3 \mathrm{~cm}$ in diameter, sampled from uteri of non-menstruating women ( $\mathrm{n}=20$ women).

Group 8. Myometrium of non-menstruating women, sampled at the distance of not less than $4 \mathrm{~cm}$ from margins of a large leiomyoma ( $\mathrm{n}=20$; autologous control).

Group 9. Leiomyomas of $>5 \mathrm{~cm}$ in diameter, sampled from uteri of non-menstruating women, ( $\mathrm{n}=20$ women).

Group 10. Myometrium of non-menstruating women, sampled at the distance of not less than $4 \mathrm{~cm}$ from margins of a large leiomyoma ( $\mathrm{n}=20$ women, autologous control).

Immunohistochemistry. Tissue specimens were fixed in $4 \%$ buffered paraformalgehyde solution, dehydrated and than embeded in paraffin. Section $(5 \mu \mathrm{m})$ were mounted onto silane-coated slides. Samples were de-waxed, rehydrated and endogenous peroxidase activity quanched using 1,5\% (v/v) solution $\mathrm{H}_{2} \mathrm{O}_{2}$ in methanol for $10 \mathrm{~min}$ and then washed in PBS-Tween $20(0,05 \%$ $\mathrm{v} / \mathrm{v}$ ) and blocked with normal goat serum for $30 \mathrm{~min}$. The sections were futher blocked with avidin-biotin-blocking solution according to the manufacturer's instruction. After this the slides were incubated with rabbit anti-aromatase polyclonal antibody (Abcam) in a humidified chamber for $22 \mathrm{~h}$ at $4^{\circ} \mathrm{C}$. After washing in PBSTween 20 sections were incubated with biotinylated goat anti-rabbit immunoglobulins (Vector Laboratories Inc.) for $30 \mathrm{~min}$. After washing, the sections were incubated with horseradish-peroxidase avidin-biotin complex (Vector) for $30 \mathrm{~min}$. The bound antibodies were visualised with diaminobenzidine (DAB) and $\mathrm{H}_{2} \mathrm{O}_{2}$ in PBS, $\mathrm{pH} 7,5$ according to supplier's instructions (Vector). Counterstaining of nuclei was performed by dipping the slides in Gill's hematoxilin. For negative controls rabbit IgG were used.

In each positively stained cell, the intensity of staining was measured as the optical density of the reaction product, with the program KS 100 VIDAS video image analyzer served by IBAS 2.5 system and a Panasonic digital camera. For each analyzed area, $173 \times 130 \mu \mathrm{m}$ average optical density per unit area was calculated. Finally, the arithmetic mean and standard deviation was calculated.

Western blotting. Tissue samples $(\sim 500 \mathrm{mg})$ were homogenized in $7 \mathrm{ml}$ buffer containing $10 \mathrm{mM}$ Tris- $\mathrm{HCl}(\mathrm{pH} 7.5), 150 \mathrm{mM} \mathrm{KCl}$, $1 \mathrm{mM}$ EDTA, and $1 \mathrm{mM}$ dithiothreitol. Homogenates were centrifuged at $1,000 \times \mathrm{g}$ for $10 \mathrm{~min}$. The supernatant was then centrifuged for $60 \mathrm{~min}$ at $105,000 \times \mathrm{g}$, and resultant microsomal pellets were resuspended in $200 \mu \mathrm{l}$ buffer containing $50 \mathrm{mM}$ Tris- $\mathrm{HCl}$, 


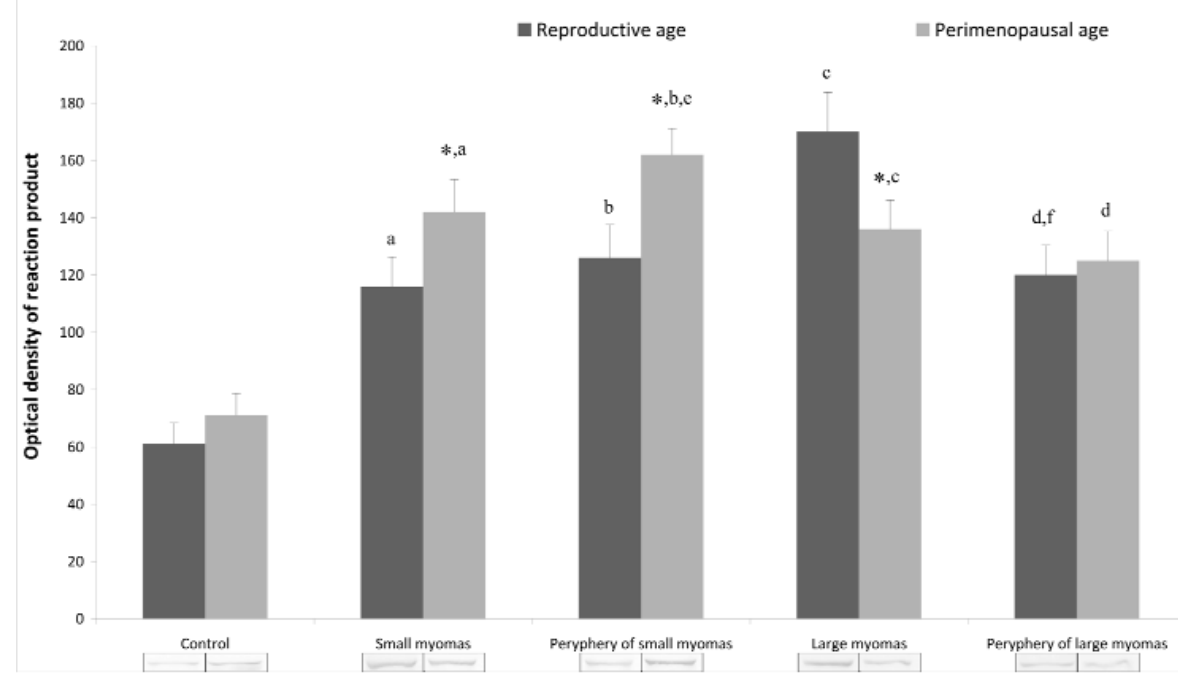

Fig. 1. Quantitative evaluation of aromatase expression. Date shown represent mean \pm SD. Differences in aromatase expression: * - in reproductive age women and perimenopausal age women; a - in small myomas and healthy myometrium; $\mathbf{b}$ - in periphery of small myomas and healthy myometrium; $\mathbf{c}-$ in large myomas and healthy myometrium; $\mathbf{d}-$ in periphery of large myomas and healthy myometrium; $\mathbf{e}-$ in small myomas and its periphery; $\mathbf{f}-$ in small myomas and its periphery, are statistically significant. There is Western blot analysis of aromatase in myometruim and leiomyoma tissue from reproductive age women and perimenopausal age women under the figure. Samples (25 $\mu \mathrm{g} / \mathrm{lane})$ were electrophoresed, blotted and aromatase was detected (see Materials and methods).
$20 \%$ glycerol, $1 \mathrm{mM}$ EDTA, and $1 \mathrm{mM}$ dithiothreitol, then frozen in liquid nitrogen. $25-\mu \mathrm{g}$ sample of microsomal protein was loaded into each lane, electrophoresed on a $10 \%$ SDS-polyacrylamide gel, and electroblotted onto a polyvinylidene difluoride membrane using a wet electroblotter. After blocking, incubation was carried out with antiaromatase antibody $(1: 1000 \mathrm{Abcam})$ at $4 \mathrm{C}$ for $20 \mathrm{~h}$ in TBS-T solution $(20 \mathrm{mM}$ Tris, $137 \mathrm{mM} \mathrm{NaCl}$, and $0.1 \%$ Tween-20, $\mathrm{pH}$ 7.6). After extensive washing, blots were incubated with biotinylated anti-rabbit IgG made in goat (Vectastain ABC-AmP Vector Laboratories, Inc.) for $30 \mathrm{~min}$ and with streptavidin and biotinylated alkaline phospatase complex for $30 \mathrm{~min}$ and developed using a BCIP/NBT Alkaline Phosphatase Substrate Kit (Vector Laboratories, Inc.).

Statistical analysis. Normal distribution of the data was confirmed by the Kolmogorov-Smirnov test. Results are presented as a mean \pm standard deviation. The Student's t-test or the Mann-Whitney Utest were performed where appropriate. The differences were regarded significant at $\mathrm{p} \leq 0.05$ level.

\section{Results}

\section{Immunohistochemistry}

Young women. Optical density of cells with expression of the evaluated protein reflects concentration of the immunocytochemical reaction product. Aromatase expression level was demonstrated to significantly increase in small myomas of young women, in which the density amounted to around $190 \%$, in related to healthy myometrium as a control value (Fig. 1; $2, \mathrm{~A}$ and $\mathrm{B})$. An analogous analysis performed at the periphery of the small myomas demonstrated that expression of the enzyme was also higher than in the control, reaching $210 \%$ of the control level (Fig. 2, A and C). Analysis of the data showed that aromatase expression at the periphery of myomas reached almost $110 \%$ of the values observed in the myoma itself.

Comparison of aromatase expression in large myomas showed that the enzyme expression reached
$280 \%$ of the control group level (Fig. 2, A and D). Unlike to the small myomas, aromatase expression measured at the periphery was slightly lower than in the myoma and comprised $200 \%$ of the control level (Fig. 2, A and E). Thus, in this case aromatase expression at the periphery of large myomas was lower than that in the myoma and it amounted to $70 \%$ of the values observed in the myoma itself.

Quantitative analysis of aromatase expression in uterine myomas of young women disclosed lower expression of aromatase in small as compared to large myomas. At the periphery of myomas aromatase expression proved to be slightly lower in direct vicinity of large myomas, as compared to vicinity of small myomas, amounting to, approximately, $95 \%$ of the latter level.

Women in a perimenopausal age. Evaluation of aromatase level in the studied uterine structures showed that in women in a perimenopausal age optical density of the reaction product in small myomas reached the level of almost $200 \%$ of the control level (Fig. 1; 2, F and $G)$. The analysis related to periphery of the myoma showed the enzyme expression level also higher than in the control $(230 \%$ of the control level; Fig. 2, F and $\mathrm{H})$. Aromatase expression at the periphery of myoma was documented to be lower than the value observed in the myoma itself $(115 \%)$.

Analysis of optical density in large myomas with aromatase expression demonstrated expression levels amounting to $190 \%$ of the control value (Fig. 2, F and I). Aromatase activity measured at the periphery of a large myoma was higher than the control value (Fig. 2, $\mathrm{F}$ and $\mathrm{J}$ ). Aromatase expression at the periphery of a large myoma was only slightly lower than in the myoma itself, amounting to around $90 \%$ of the value noted in the myoma. 

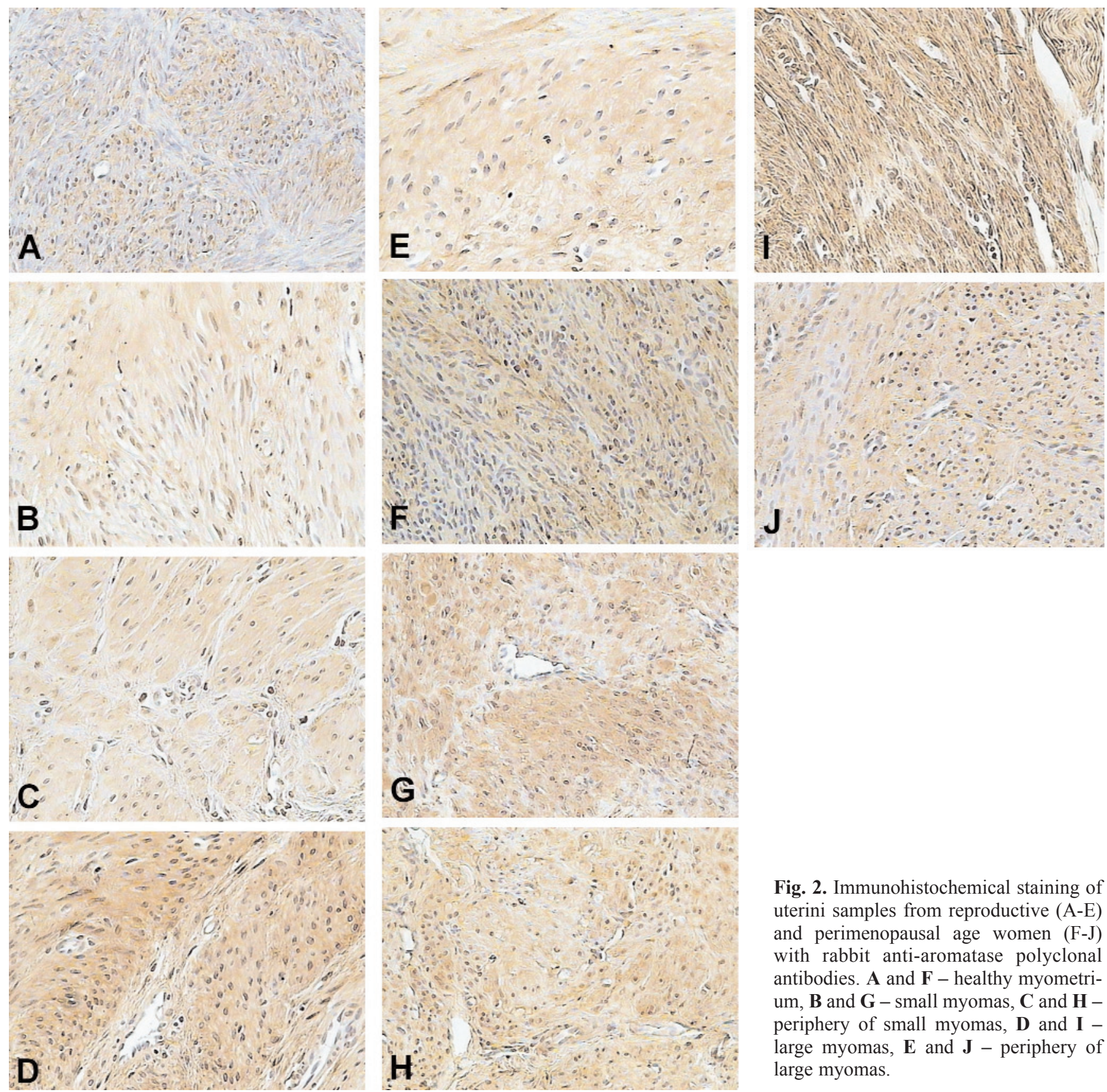

Fig. 2. Immunohistochemical staining of uterini samples from reproductive (A-E) and perimenopausal age women (F-J) with rabbit anti-aromatase polyclonal antibodies. A and $\mathbf{F}$ - healthy myometrium, $\mathbf{B}$ and $\mathbf{G}$ - small myomas, $\mathbf{C}$ and $\mathbf{H}-$ periphery of small myomas, $\mathbf{D}$ and $\mathbf{I}$ large myomas, $\mathbf{E}$ and $\mathbf{J}$ - periphery of large myomas.

In women of perimenopausal age aromatase expression in large myomas proved to be lower than in small myomas, reaching around $95 \%$ of the level typical of small myomas. Quantitative analysis of aromatase expression in the myomas of perimenopausal women indicated lower expression in large myomas than in small one $(95 \%)$. The expression its enzyme measured at the periphery of large myomas was lower than at the periphery of small myomas $(75 \%)$.

Effect of patient's age. Comparison of the content of aromatase expression product demonstrated the lower level of the enzyme in control samples isolated from young women than in samples originating from women in a perimenopausal age (Fig. 1). In small myomas originating from women in a perimenopausal age aromatase expression level reached $120 \%$ of the value demonstrated in small myomas originating from the group of young women. If aromatase expression was evaluated at the periphery of small myomas in the two age groups, its higher level was disclosed in older women, in whom the level reached $127 \%$ of the value noted in young women.

Analysis of the enzyme expression in large myomas showed its lower level in women in a perimenopausal age, in whom it amounted $80 \%$ of the 
Table 1. Level of aromatase protein in uterus tissue samples from myometrium and leiomyomas from young and perimenopausal age women. Quantitative analysis indicated, that aromatase level in myometrium perimenopausal age women is $110 \%$ those in young women.

\begin{tabular}{|l|c|c|c|c|}
\hline \multirow{2}{*}{ Control } & \multicolumn{2}{|c|}{ Small myomas } & \multicolumn{2}{c|}{ Large myomas } \\
\cline { 2 - 5 } & Myomas & Myometrium & Myomas & Myometrium \\
\hline Reproductive age women -100 & $165^{\mathrm{a}}$ & $185^{\mathrm{b}}$ & $210^{\mathrm{d}}$ & $180^{\mathrm{c}}$ \\
\hline Perimenopausal age women -100 & $175^{\mathrm{ae}}$ & $205^{\mathrm{b}}$ & $160^{\mathrm{d}}$ & $150^{\mathrm{c}}$ \\
\hline
\end{tabular}

Differences in aromatase expression: ${ }^{*}$ - in reproductive age women and perimenopausal age women; a in small myomas and healthy myometrium; ${ }^{b}$ in periphery of small myomas and healthy myometrium; ${ }^{\mathrm{c}}$ in large myomas and healthy myometrium; $\mathrm{d}$ in periphery of large myomas and healthy myometrium; e in small myomas and its periphery, are statistically significant for $\mathrm{p}=0.05$.

level observed in young women. The level of reaction product measured at the periphery of large myomas was the same lower in older women like in the young women.

\section{Western blot analysis}

Comparing expression of aromatase in myometrium of females at various age it was found slightly higher in samples originating from perimenopausal females although the difference failed to be significant.

For a better and more clear evaluation of changes in aromatase expression a quantitative analysis was conducted exclusively in the same age groups, accepting as the $100 \%$ value the level of the expression noted in the pure control.

The detected aromatase expression level in small myomas sampled from uteri of young women was clearly higher than in the control, amounting to $165 \%$, and the difference was significant. Even higher expression level was observed in large myomas, in which expression level of the protein amounted to $210 \%$ of the control level (Table 1; see also Fig. 1).

The level of aromatase expression measured at the periphery of myomas originating from uteri of young women was higher than that in the control, amounting to $185 \%$ and $180 \%$, respectively, in small and large myomas.

In analysis of aromatase expression levels in the myomas and in their direct vicinity, in the cases of both small and large myomas the levels showed no significant differences. Analysis of changes in aromatase expression in uteri of postmenopausal women the course of the changes manifested a similar course to that noted in young women. The aromatase expression level in small myomas isolated from uteri of perimenopausal women was higher than in the control, amounting to $175 \%$, and the change was statistically significant. The aromatase expression level observed in large myomas in the samke age group was slightly lower and amounted to $160 \%$ of the control level.

Aromatase expression measured at the periphery of the myomas was also higher than that seen in the control. In cases of small and large myomas the levels amounted to $205 \%$ and $150 \%$, respectively (Table 1 ; see also Fig. 1) and the differences proved to be significant.

Evaluating aromatase expression levels in myomas and the surrounding myometrium in the older age group the aromatase expression in small myomas proved to be significantly lower than in the surrounding myometrium. In large myomas and their surrounding myometrium the difference proved to be insignificant.

\section{Discussion}

Smooth muscle myomas of the uterus are the most frequent tumours of the female genital tract. In as many as $75 \%$ cases histerectomy preparations following surgery conducted for various reasons were found to contain uterine smooth muscle myomas [15]. The obtained clinico-pathological data, involving at least a few hundreds of problematic cases of uterine smooth muscle myomas and other detailed studies conducted by the same group of pathologists, provide at present the principal source of data for clinical management of the difficult group of tumours [16,17].

Determination of aromatase expression in cells of myomas and other estrogen-dependent tumours seems significant from the point of view of pathogenesis of the tumours and potential directions of therapy. The increasingly numerous studies suggest that in women of postmenopausal age estrogens localised in tumour cells originate from in situ aromatization in the pathologically altered tissue and that they act locally as a mitogenic factor, facilitating tumour growth independently of estrogen concentrations in the serum.

In our studies myometrium sampled from women in whom no myomas were detected has been found to express aromatase. Its level has been low but similar in the two age groups, of young women and women in the perimenopausal age. This indicates that upon access of androgens they can be aromatized to estrogens in the uterus. This may result in a locally augmented level of estrogens in myometrium, the level which may exceed physiological concentrations.

The observations are not fully confirmed by reports of other authors: it some of the reports slightly distinct 
results have been presented. Their authors stress that smooth muscle myoma tissue becomes a source of estrogen when it is exposed to endogenous sex steroids. The smooth muscle myoma tissue contains its own aromatase, a microsomal enzyme, which catalyzes conversion of androgens to estrogen even if this cannot happen in a normal myometrium [10]. The exogenous estrogen, produced by smooth muscle myomas, probably promotes growth in an autocrine or intracrine manner [11]. Production of estrogen in smooth muscle myomas is inhibited by treatment with GnRH agonist in situ [18] and in vivo [19] due to inhibition of aromatase activity. Shozu et al. [20] found that size of smooth muscle myoma was directly related to expression of aromatase mRNA in various smooth muscle myomas within the same uterus. The correlation could not be observed for aromatase mRNA levels noted in distinct patients, carrying smooth muscle myomas of a significant size [20]. In a smooth muscle myoma tissue conversion of estrone to estradiol is three-fold more intense than in a respective myometrium, which corresponds to higher expression of mRNA for 17 $\beta$-hydroxysteroid dehydrogenase (HSD) type I [20]. The enzyme catalyzes reciprocal conversion of adrostenedione and testosterone, as well as of estrone and estradiol and, together with aromatase, plays a significant role.

In postmenopausal women, circulating estrogens originate, first of all, from peripheral conversion of androgens synthesized both in ovaries and in suprarenal glands. Such a conversion takes place mainly in peripheral tissues but, as proven by results of studies on expression of aromatase gene, local synthesis of androgens occurs also in endometrial adenocarcinoma even if the amount of the hormone produced there is not sufficient to increase estrogen pool in the peripheral blood. Even if no direct proof is available for the role of estrogen in in situ growth of myoma cells, the experiment with use of a circulating androstenedione as a substrate showed that myoma cells are capable of synthesizing sufficient amounts of estrogens to promote their own growth [18].

In women at their reproductive age the amount of circulating estrogen, produced by ovaries, is substantial as compared to the in situ synthesized estrogen. Thus, estrogen in situ may belong to factors which are important for growth of myoma cells. On the other hand, following cessation of ovarian follicle growth the in situ produced estrogen may represent its only available source for myoma tissue in postmenopausal women. Since blood androstenedione levels (5-10 $\mathrm{nmol} / \mathrm{l}$ ) in women at early menopause continue to persist close to $\mathrm{K}_{\mathrm{M}}$ value for aromatase, significant amounts of estrogen can be synthesized in situ taking advantage of plasma androstenedione [11]. Thus, estrogen produced in situ may prevent abrupt regres- sion of myoma cells due to the complete disappearance of the ovarian estrogen [18]. In fact, most of myomas demonstrate no perceptible traits of regression in the course of the first 6 months of natural menopause despite the abrupt decrease in plasma estradiol concentration and the regression is clearly slower in women treated with GnRH agonists. Size of a myoma may decrease with age but the amount of estrogen which is produced in situ does not decrease until suprarenal production of androstenedione becomes reduced.

The above considerations acquire an additional dimension in patients with uterine myomas. In such a case, particular attention should be devoted to results pertaining aromatase activity in tests performed on samples from young women. In this age group we have noted a particularly strongly expressed aromatase activity, first of all in large myomas. Such a situation may point to severe consequences for health of the patients. The mechanism due to which myoma maintains high level of aromatase expression still remains unknown. A few genes demonstrate overexpression in myomas, as compared to the surrounding myometrium [21]. Some of the genes are stimulated by estrogen and manifest expression level normal for myometrium in conditions of hypoestrogenism, induced by $\mathrm{GnRH}$ agonists. Although treatment with GnRH agonists decreases also expression of aromatase in myomas, the estrogen-linked control does not seem to be related to aromatase since treatment with estradiol does not affect aromatase expression level in cultures of myoma cells [18]. The only suggestion which can be put forward as to the mechanisms maintaining aromatase overexpression reflects the fact that no significant differences have been noted in aromatase expression between myoma cells and ex vivo cultured myometrial cells. When myoma cells become isolated from tissue and placed in a culture, aromatase expression decreases by $5-20 \%$ as compared to the values noted in the tissue $[10,18,22]$. In an ex vivo culture both basal and induced levels of expression are identical in myoma cells and in myometrium originating from the same uterus. On the other hand, supplementation with myoma homogenate recovered aromatase expression in myoma cells, which reached levels typical for the tissue [22]. The results are consistent with the observation that myoma cells preserve the ability to express aromatase in response to an adequate stimulus in the tissue and reduce the expression to basal levels when the stimulus is removed, as it happens in an ex vivo culture. Already in preliminary discussions on factors which might modify the expression, IL-1b secreted by myoma cells represented the candidate for such an in vivo stimulating factor.

Another potential explanation for aromatase overexpression in myomas involves activity of mitogen- 
activated protein kinase (MAPK), stimulated by a variety of extracellular signals, including growth factors. Activity of MAPK is indispensable for a full induction of mRNA for aromatase and for its activity [23]. As compared to myometrium, expression of MAPK and its activity increase in the myoma tissue, probably due to differences in expression of the extracellular matrix between the tissues [24]. Bypassing certain details, it may be accepted that increase in MAPK activity may participate in aromatase overexpression in myomas.

Activity of aromatase in myoma tissue has been reported in literature of the subject Nevertheless, distinct opinion can be encountered on presence of the enzyme in endometrium involved by the pathological process. Sumitani et al. [11] demonstrated low amounts of mRNA for aromatase gene in endometrium of myomatous uteri. They demonstrated also that expression of CYP19 gene within uterine myomas was higher than in the surrounding myometrium and endometrium. Therefore, it seems possible that myomas, similarly to other tumours, release factors which promote local steroidogenesis. The question arises if demonstration of local steroidogenesis in endometrium of myomatous uteri does not represent a prognostically negative index, pointing to the risk of neoplastic transformation in the tissue. Clinical studies indicate that uterine adenocarcinoma in $30 \%$ coincides with myomas. The obtained results provoke further investigations, aimed at clarification of aromatase role in pathology of the disease.

Literature reports on the subject are very scant. In the innumerous reports on local synthesis of estrogens in uterine myomas an attempt has been made to resolve whether aromatase present in uterine myomas plays an important role in their growth and whether myomas synthesize sufficient amounts of estrogens to promote myoma growth. Myoma cells are thought to be capable of synthesizing sufficient amounts of estrogens and local aromatization in myoma tissues is thought to be responsible for the cell growth-promoting affect.

Continuing the analysis of aromatase role one should keep in mind our important observation that expression of aromatase has been evident in myometria obtained from patients with myomas. Although the expression level has been lower than in myomas, it has been clearly higher than in normal myometria. It should be noted that the samples have been isolated outside of the so called surgical safety margin and, thus, they have represented uterine region in which no myomatous relapse should develop. Our studies have demonstrated that in such a region aromatase expression level in favourable conditions has been sufficiently high to promote de novo development of a myoma. The problem of how far from the neoplastic lesion aro- matase expression is significantly elevated remains unsolved. This will require further arduous investigations.

\section{References}

[1] Pandis N, Heim S, Bardi G, Flodérus UM, Willén H, Mandahl N, Mitelman F. Chromosome analysis of 96 uterine leiomyomas. Cancer Genet Cytogenet. 1991;55:11-18.

[2] Townsend DE, Sparkes RS, Baluda MC, McClelland G. Unicellular histogenesis of uterine leiomyomas as determined by electrophoresis by glucose-6-phosphate dehydrogenase. Am J Obstet Gynecol. 1970;107:1168-1173.

[3] Arici A, Sozen I. Expression, menstrual cycle-dependent activation, and bimodal mitogenic effect of transforming growth factor-beta1 in human myometrium and leiomyoma. Am J Obstet Gynecol. 2003;188:76-83.

[4] Maruo T, Matsuo H, Samoto T, Shimomura Y, Kurachi O, Gao Z, Wang Y, Spitz IM, Johansson E. Effects of progesterone on uterine leiomyoma growth and apoptosis. Steroids. 2000;65:585-592

[ 5] Walker CL. Role of hormonal and reproductive factors in the etiology and treatment of uterine leiomyoma. Recent Prog Horm Res. 2002;57:277-294.

[6] Cole SL. An internist's observations of patients on long-term contraception. J Reprod Med. 1970;5:175-178.

[ 7] Puukka MJ, Kontula KK, Kauppila AJ, Janne OA, Vihko RK. Estrogen receptor in human myoma tissue. Mol Cell Endocrinol. 1976;6:35-44.

[ 8] Wilson EA, Yang F, Rees ED. Estradiol and progesterone binding in uterine leiomyomata and in normal uterine tissues. Obstet Gynecol. 1980;55:20-24.

[ 9] Tamaya T, Fujimoto J, Okada H. Comparison of cellular levels of steroid receptors in uterine leiomyoma and myometrium. Acta Obstet Gynecol Scand. 1985;64:307-309.

[10] Bulun SE, Simpson ER, Word RA. Expression of the CYP19 gene and its product aromatase cytochrome P450 in human uterine leiomyoma tissues and cells in culture. $J$ Clin Endocrinol Metab. 1994;78:736-743.

[11] Sumitani H, Shozu M, Segawa T, Murakami K, Yang HJ, Shimada $\mathrm{K}$, Inoue $\mathrm{M}$. In situ estrogen synthesized by aromatase P450 in uterine leiomyoma cells promotes cell growth probably via an autocrine/intracrine mechanism. Endocrinology. 2000;141:3852-3861

[12] Otubu JA, Buttram VC, Besch NF, Besch PK. Unconjugated steroids in leiomyomas and tumor-bearing myometrium. $\mathrm{Am}$ J Obstet Gynecol. 1982;143:130-133.

[13] Pasqualini JR, Cornier E, Grenier J, Vella C, Schatz B, Netter A. Effect of Decapeptyl, an agonistic analog of gonadotropinreleasing hormone on estrogens, estrogen sulfates, and progesterone receptors in leiomyoma and myometrium. Fertil Steril. 1990;53:1012-1017.

[14] Madej P, Plewka A, Madej JA, Dzimira S, Nowak M, Plewka D, Nowaczyk G. Immunohistochemical localization of telomerase in myomas and in uterine myometrium. Pathol Res Pract. 2008;204:637-642.

[15] Cramer SF, Patel A. The frequency of uterine leiomyomas. Am J Clin Pathol. 1990;94:435-438.

[16] Bell SW, Kempson RL, Hendrickson MR. Problematic uterine smooth muscle neoplasms. A clinicopathologic study of 213 cases. Am J Surg Pathol. 1994;18:535-558.

[17] Kempson RL, Hendrickson MR. Smooth muscle, endometrial stromal, and mixed Müllerian tumors of the uterus. Mod Pathol. 2000;13:328-342.

[18] Shozu M, Sumitani H, Segawa T, Yang HJ, Murakami K, Inoue M. Inhibition of in situ expression of aromatase P450 in 
leiomyoma of the uterus by leuprorelin acetate. $J$ Clin Endocrinol Metab. 2001;86:5405-5411.

[19] Ishihara H, Kitawaki J, Kado N, Koshiba H, Fushiki S, Honjo H. Gonadotropin-releasing hormone agonist and danazol normalize aromatase cytochrome $\mathrm{P} 450$ expression in eutopic endometrium from women with endometriosis, adenomyosis, or leiomyomas. Fertil Steril. 2003;79(Suppl 1):735-742.

[20] Shozu M, Murakami K, Inoue M. Aromatase and leiomyoma of the uterus. Semin Reprod Med. 2004;22:51-60.

[21] Andersen J. Growth factors and cytokines in uterine leiomyomas. Semin Reprod Endocrinol. 1996;14:269-282.

[22] Shozu M, Sumitani H, Segawa T, Yang HJ, Murakami K, Kasai T, Inoue M. Overexpression of aromatase P450 in leiomyoma tissue is driven primarily through promoter I.4 of the aromatase P450 gene (CYP19). J Clin Endocrinol Metab. 2002;87:2540-2548.

[23] Shozu M, Sumitani H, Murakami K, Segawa T, Yang HJ, Inoue M. Regulation of aromatase activity in bone-derived cells: possible role of mitogen-activated protein kinase $J$ Steroid Biochem Mol Biol. 2001;79:61-65.

[24] Chegini N, Verala J, Luo X, Xu J, Williams RS. Gene expression profile of leiomyoma and myometrium and the effect of gonadotropin releasing hormone analogue therapy. J Soc Gynecol Investig. 2003;10:161-171.

Submitted: 18 March, 2009 Accepetd after reveiws: 20 June, 2009 